\title{
СЛУЧАИ НЕТИПИЧНОГО ТЕЧЕНИЯ САХАРНОГО ДИАБЕТА 1 ТИПА У ДЕТЕЙ С РАННИМИ НЕВРОЛОГИЧЕСКИМИ ОСЛОЖНЕНИЯМИ
}

\author{
А.С. Филькова, Л.И. Зильберман, Д.Н. Лаптев \\ ФГБУ «Научный исследовательский институт эндокринологии», Москва
}

\begin{abstract}
АКТУАЛЬНОСТЬ ТЕМЫ: известно, что основные факторы риска возникновения диабетической полинейропатии у детей включают в себя: большую продолжительность заболевания, плохой гликемический контроль и в последнее десятилетия наличие полиморфизмов гена альдозоредуктазы. В соответствии с последними клиническими рекомендациями ISPAD 2018 начало скринирования на наличие диабетической полинейропатии (ДН) должно проводится с 11 лет при длительности заболевания от 2 до 5 лет. Между тем по данным отдельных исследований около 25\% пациентов на момент манифестации СД1 уже имеют признаки субклинической полинейропатии, поэтому предлагается проводить ежегодный скрининг для раннего выявления поражения нервной системы всем детям с продолжительностью заболевания более 3 лет, а подросткам с момента манифестации. Золотым стандартом диагностики ДН является исследование нервной проводимости (ЭНМГ). Однако более распространенным и простым методом диагностики на сегодняшний день является клиническое исследование температурной, вибрационной и тактильной чУвствительности.
\end{abstract}

АНАЛИЗ КЛИНИЧЕСКИХ СЛУЧАЕВ. ПацИентка, 12 лет, обратилась ФГБУ НМИЦЭ в связИ с жалобами на полиурию, полидипсию, снижение выносливости, нарастание гликемии. Сахарный диабет 1 типа диагностирован полтора года назад, при диагностике: гликемия 18 ммоль/л, гликированный гемоглобин -14,4\%, инсулин - 5,8 мкЕд/мл, глюкозурия, кетонурия, от инсулинотерапии отказались родители. Проводилась терапия ПССП на фоне строгой низкоуглеводной диеты на 3-4 ХЕ в сутки. Через полгода от дебюта заболевания: гликированный гемоглобин -6,7\%, инсулин - 7,9 мкЕд/мл, С-пептид - 518 пмоль/л. Самочувствие удовлетворительное. В течение следующего года гликированный гемоглобин от 5,9 до 6,4 ммоль/л. При обследовании в НМИЦЭ: SDS индекса массы тела: -2.1 , кетонурия, глюкозурия, гликированный гемоглобин $-10,3 \%$, в неврологическом статусе: головная боль, снижение температурной и вибрационной чувствительности. Инициирована инсулинотерапия.

Пациент, 17 лет обратился в связи с нетипичным течением заболевания. В возрасте 14 лет при обследовании по поводу длительного субфебрилитета в общем анализе мочи выявлена глюкозурия, гликемия натощак 10,2 ммоль/л, кетоны 0,2 ммоль/л, госпитализирован: гликированный гемоглобин 7,7\%, с-пептид 487 пмоль/л (343-1803), инсулин 41 пмоль/л (13-161), повышение титра специфических аутоантител ICA 160 ед, GAD 56.3 ME/мл, IA-2 1,6 ME/мл, аглюкозурия, акетонурия. Назначена диета с ограничением легкоусвояемых углеводов, метформин в стартовой дозе 500 мг, в дальнейшем проводилась постепенное повышение до 2000 мг в сутки, на фоне чего колебания гликемии от 4 до 8 ммоль/л. При обследовании в НМИЦЭ: гликированный гемоглобин 6,8\%, по данным ОГТТ диабетический уровень гликемической кривой, сниженная секреция инсулина и с-пептида, в отделении колебания гликемии от 7 до 10 ммоль/л, с единичными повышениями до 14 ммоль/л после еды. Выявлена дистальная полинейропатия, сенсорный тип (снижение температурной и вибрационной чувствительности). У пациента инициирована инсулинотерапия.

Выводы. В обоих случаях диагностировано клиническое течение дистальной диабетической полинейропатии, сенсорного типа, не смотря на удовлетворительный уровень гликированного гемоглобина и небольшую длительность заболевания. Предположительно причиной столь раннего развития дистальной полинейропатии стало позднее назначение инсулинотерапии. Учитывая данные мировых исследований скринирование дистальной полинейропатии возможно нужно проводить начиная с диагностики заболевания. 